\title{
Pascalis M. Kitromilides: A Discourse on the Island of Cyprus
}

Brunehilde Imhaus

\section{(2) OpenEdition}

1 Journals

Édition électronique

URL : https://journals.openedition.org/ceb/826

DOI : $10.4000 /$ ceb.826

ISSN : 2261-4184

Éditeur

INALCO

\section{Édition imprimée}

Date de publication : 30 mars 2011

Pagination : 401-403

ISBN : 978-2-85831-189-7

ISSN : 0290-7402

\section{Référence électronique}

Brunehilde Imhaus, "Pascalis M. Kitromilides: A Discourse on the Island of Cyprus », Cahiers

balkaniques [En ligne], 38-39 | 2011, mis en ligne le 05 décembre 2011, consulté le 06 juillet 2021. URL http://journals.openedition.org/ceb/826 ; DOI : https://doi.org/10.4000/ceb.826

Ce document a été généré automatiquement le 6 juillet 2021.

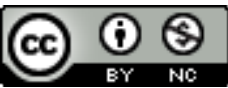

Cahiers balkaniques est mis à disposition selon les termes de la Licence Creative Commons Attribution - Pas d'Utilisation Commerciale 4.0 International. 


\title{
Pascalis M. Kitromilides: A Discourse on the Island of Cyprus
}

\author{
Brunehilde Imhaus
}

\section{RÉFÉRENCE}

Pascalis M. Kitromilides: A Discourse on the Island of Cyprus, 122 pages; cinq illustrations, Institut Hellénique d'Études Byzantines et post Byzantines de Venise, Graecolatinitas Nostra, Fonti 7, Venise 2006. ISSN 1108-4707, ISBN 960-7743-37-7

1 Cet ouvrage livre aux chercheurs la transcription, (en italien et en anglais), annotée et commentée du manuscrit de Giorgio Denores, composé au début du XVIIe siècle et conservé auprès de la Bibliothèque Palatine de Parme ( Regia Biblioteca di Parma, Palatini MSS. 461).

2 Giorgio Denores : Discorso sopra l'Isola di Cipri con le Ragioni della Vera Successione in Quel Regno.( Discours sur l'ile de Chypre et les raisons de la juste succession dans ce Royaume).

3 P. Kitromilides entend à travers cette publication montrer que, selon G. Denores, la question chypriote, examinée à travers des prétentions dynastiques remontant à la fin du Moyen Âge, met en jeu des concepts interétatiques européens, annonçant la pensée de Grotius, alors que l'Europe happée par la guerre de Trente Ans, délaisse en partie, au moins sur le plan diplomatique, la Méditerranée Orientale.

4 P. Kitromilides, dans une longue introduction, présente l'auteur et la structure du texte de G. Denores.

5 Giorgio Denores, fils de Laura Denores, naquit à Rome en 1619 et prit le patronyme prestigieux de sa mère qui descendait d'une des plus illustres familles latines de Chypre. Giorgio fut élevé sous la férule de son oncle maternel, Pietro Denores, né en 1571 dans l'île de Chypre, -- à quelques semaines de la conquête de Chypre par les Ottomans -- fils, lui-même, de Jason Denores, personnage connu des sources chypriotes et promu professeur à l'Université de Padoue après le désastre de la conquête. Pietro 
Denores, homme de lettres, fut particulièrement versé dans l'historiographie. Il fut par ailleurs secrétaire des papes Clément VIII et Urbain II. Il n'est pas étonnant que le jeune Giorgio ait suivi la voie familiale et se soit tourné vers les Lettres et l'Histoire. Trois manuscrits de son Discours sont conservés qui ne diffèrent que fort peu. L'attribution du Discours d'abord à Pietro Denores par L. Scarabelli, en 1840, est erronée et P. Kitromilides, s'appuyant sur les travaux récents de P.O. Kristeller, rend justice à son véritable auteur, Giorgio. Ce Discorso sopra l'isola di Cypri con le ragioni della vera successione in quel Regno composé d'une trentaine de pages, comprend une courte introduction suivie d'une brève histoire de l'île de Chypre, puis vient le corps du texte : les raisons qu'ont les cinq prétendants à la succession au royaume de Chypre, raisons que G. Denores réfute en conclusion. Ceci nous montre bien que, soixante ans après la prise de Chypre par les Ottomans, la légitime possession de l'île restait une question ouverte dans les relations diplomatiques du monde européen.

Dans ce texte P. M. Kitromilides remarque combien le jeune auteur, outre sa très grande érudition, est fort attentif aux intrigues diplomatiques européennes face aux questions dynastiques.

7 Selon G. Denores, les prétendants dotés d'une certaine légitimité au royaume de Chypre sont :

Tout d'abord :

- le Duc de Savoie, en tant qu'apparenté à la famille de Lusignan.

- Les descendants de Henri de Lusignan, prince de Galilée et frère du roi Janus.

- La République de Venise qui, après l'abdication forcée de la reine Caterina Cornaro, a gouverné l'île jusqu'à la conquête ottomane.

- La République de Gênes qui a occupé Famagouste durant près d'un siècle.

- Le Sultan du Caire, successeur du sultan mamelouk vainqueur du roi Janus de Lusignan, à la bataille de Kirokitia (1421), lequel devint, lui et ses successeurs tributaires des sultans égyptiens.

8 Très au fait des questions dynastiques, G. Denores dresse un tableau généalogique de la famille des Lusignan et mentionne tous les descendants du roi de Chypre et leurs alliances. Il analyse les raisons qu'ont ces cinq prétendants à briguer le royaume de Chypre et il les rejette toutes en bloc.

G. Denores, tout en regrettant que la tentative faite par le grand-duc de Toscane, Ferdinand, de récupérer l'île de Chypre à son profit n'ait pas abouti, la libérant ainsi de l'oppression ottomane, ajoute que si les nations européennes avaient appuyé la Toscane, un esprit bien intentionné aurait prouvé que la Maison des Médicis avait autant de droits que les Lusignan sur cette île !

Pour G. Denores, tout s'est joué durant l'époque médiévale, et c'est là qu'il convient de rechercher les raisons avancées par les uns et les autres. L'auteur reconnait que si l'Empire byzantin n'avait pas été anéanti, il serait le seul prétendant légitime ; $\mathrm{P}$. Kitromilides relève que cette assertion est curieuse pour un érudit qui espérait faire une carrière politique auprès de la Cour Pontificale.

11 P. Kitromilides tente d'expliciter la pensée qui amène le jeune historiographe qu'est G. Denores, à rejeter tous les candidats cités à la possession de l'île. Pour P. Kitromilides, $G$. Denores considère que toutes ces prétentions dynastiques se réfèrent aux normes féodales, ce qui leur donne en quelque sorte le droit de revendiquer cet héritage ; mais dans la pensée politique italienne prévalent, en ces débuts du XVIIe siècle, des 
exigences de modernité, même si la raison d'État doit encore passer sous le contrôle de principes moraux. G. Denores considère que la possession légitime de l'île de Chypre ne peut être liée à un droit dynastique, encore moins à la force, mais à la seule nation qui lui rendra sa liberté et la justice. Pour lui, l'établissement de règles de justice internationale est inhérent à la conduite des États, tout comme il doit être le fondement des relations inter étatiques.

12 Ce Discorso, en inaugurant l'historiographie de la Question Chypriote, témoigne des espoirs que conservaient les Chypriotes exilés de voir abattu le joug ottoman sous la conduite d'une puissance chrétienne ; espoirs caractéristiques, selon P. Kitromilides, des cultures de l'exil.

13 Ce texte peut donc intéresser les historiens médiévistes et les historiens des périodes plus récentes, tout autant que les spécialistes de philosophie politique. On ne peut que rendre justice à P. Kitromilides d'avoir sorti ce Discorso de l'ombre, ainsi qu'à l'Institut Hellénique d'Études Byzantines et post Byzantines de Venise pour en avoir assuré une publication soignée.

INDEX

motsclesel Kúr $\rho \circ \varsigma$

motsclesmk КИПАР 